\title{
Cultural Wellbeing Index: A Dynamic Cultural Analytics Process for Measuring and Managing Organizational Inclusion as an Antecedent Condition of Employee Wellbeing and Innovation Capacity
}

\author{
Cameron Lister \\ University of Louisville \\ Underestimated People of Purpose (UPOP PBC) \\ Sonali S. Salunkhe \\ University of Louisville \\ Molly O'Keefe \\ University of Louisville \\ Hannah E. Payne \\ Underestimated People of Purpose (UPOP PBC) \\ Theodore Edmonds \\ University of Louisville \\ Underestimated People of Purpose (UPOP PBC)
}

The purpose of this study was to validate an inclusive, holistic, evidence-based index to measure the impact of organizational culture on employee wellbeing. This study utilized a new Cultural Wellbeing Index (CWI), a composite of other validated cultural metrics including inputs of hope, trust, and belonging. Internal validity of the index was measured using Cronbach's alpha and Pearson correlation. Four logistic regression models were completed to test the correlative power of the CWI to employee health, retention, engagement, and job satisfaction. CWI shows strong internal validity and strong correlative and predictive power with employee wellbeing metrics among the population surveyed.

Keywords: corporate culture, cultural wellbeing, hope, trust, belonging, innovation

\section{INTRODUCTION}

The World Health Organization (WHO) states that "the systematic neglect of culture is the single biggest barrier to advancing the highest attainable standard of health worldwide" (Napier et al., 2014). Likewise, a recent study of 1,000 HR leaders by Virgin Pulse shows workplace culture is one of the greatest barriers to increased employee wellbeing and engagement (Kohll, 2018). Culture is a dynamic process 
which informs individual perceptions of wellbeing and how diverse groups make sense of what they experience in their lives (Kagawa Singer, 2012). Therefore, employee engagement and subsequently employee wellbeing in the American workforce is fundamentally a cultural challenge ("Gallup," 2017). Because the workplace is a micro-community which reflects a plurality of greater societal paradigms, the idea of "cultural wellbeing" in the workplace is an interesting new area to consider for collaboration between businesses and public health researchers.

Cultural wellbeing comes from being valued for the differences that define us. Across all sectors, diversity and inclusion efforts are surging as key social and operational imperatives in business. Organizations that achieve high levels of cultural wellbeing may be better positioned to empower diverse members in a way that supports full, individual participation in the goals and the culture of employer organizations (Matsuura, 2005). In fact, recent reports from Techstars, Deloitte, U.S. Chamber of Commerce Foundation, and the Human Rights Campaign Equality Index all found that culture is key to innovation output and market performance ("U.S. Chamber of Commerce Foundation," 2019; "Human Rights Campaign Foundation," 2019; "Roadmap \& Assessment Report," 2019; Smith \& Yoshino, 2019). However, in efforts to shape and manage culture, organizations must be able to identify and measure the correct leverage point ("Gallup," 2018). For instance, leaders have a significant amount of control in how they adapt corporate policy and benefits to external influences, while at the same time have little control over how these changes are perceived by their diverse workforce (Trompenaars, 1993). Therefore, developing predictive, analytical tools that account for and better align an organization's culture with the diverse cultural influencers of its employees and stakeholders may potentially expand opportunities for collaboration between public health and private sector interests while accelerating quality improvement efforts toward enhanced employee wellbeing and community health.

\section{Employee Wellbeing}

One of the greatest barriers to public health expansion in the modern era is entry into and meaningful collaboration with the private sector (Desalvo et al., 2017; Fry, 2020). Considering the COVID-19 pandemic, the growing prevalence of chronic disease, and other complex population health challenges, many companies are increasingly prioritizing hiring experts in public health to help develop a centralized strategy for their employee's health, safety, and wellness ("Harvard School of Public Health," 2020). To date, some of the more impressive gains in public-private collaborations include the creation of health apps and the adoption of worksite wellness programs by corporations large and small. These efforts have largely been under the guise of a return on investment (ROI) based on healthcare cost savings and employee productivity. However, these programs may not produce the results that corporations and wellness companies once hoped were possible (Lieberman, 2019). In one randomized clinical trial conducted in a large U.S. company, researchers reported that, after 18 months, employees at worksites with a worksite wellness program reported no significant differences in many self-reported health behaviors, including mental health and wellbeing, health screenings, sleep, and nutrition. There was also no significant difference in clinical markers of health (e.g., cholesterol and blood pressure measurements), healthcare spending or utilization, absenteeism, tenure, or job performance (Song \& Baicker, 2019).

Similarly, researchers from the RAND corporation concluded from a study of 600,000 employees across seven employers that wellness programs have little effect on how much employers spend on healthcare for their employees (Mattke et al., 2014). One reason for this failure may be that wellness programs do not attract those who would most benefit from participating in their offerings, with employees reporting the highest levels of healthy behaviors at baseline the most likely to participate in such programs (Jones, Molitor, \& Reif, 2019). Some companies do report long-term improvement in employee health metrics and improvements in health care costs due to worksite wellness initiatives, but such successes require careful, long-term organization and planning not often adopted by many organizations, including involving multiple levels of leadership, individualizing programs for employee's unique needs, and making programs accessible and integrated into employee's lives (Berry, Mirabito, \& Baun, 2010).

While several worksite wellness companies point to strong metrics for ROI (i.e., cost savings, fewer sick days, etc.), value of investment (VOI) or increased business performance and increased talent 
acquisition and retention has to date been difficult, if not impossible to accurately measure (Aldana, 2020). Research by the Kaiser Family Foundation has suggested that worksite wellness has become more of a central employment benefit or sign of a well-rounded workplace rather than a disease management or cost saving tool (KAISER FAMILY FOUNDATION, Claxton, Rae, Long, \& Damico, 2018). The question remains how public health can effectively translate the long-term benefits of investing in employee wellbeing to align with the short-term economic goals of corporate America. An answer to this may be hiding in plain sight. Despite the best efforts of corporate innovators and public health professionals, programs have over time neglected one of the key drivers of health among populations: culture.

\section{Organizational Culture}

Organizations are increasingly facing pressure to adapt to not only technological advances, but also cultural and social movements (Hofstede, 2011; Jarrahi, 2018). The cultures of nations and organizations are both alike in the sense that they are each informed by their own rituals, symbols and values (Hofstede, 2011). Some organizational culture and employee development models focus on employee behaviors as the lever of change (Champion \& Skinner, 2008; Fogg, 2009; Prochaska \& Velicer, 1997; Seligman, 2018), while others focus on cultivating employee-level psychological happiness and hedonic wellbeing (Robinson, 2009). These approaches largely center on changing the individual without changing the underlying ecology of the organizational culture. This 'ecological fallacy' is a limiting paradigm for those organizations seeking to create cultures of inclusion in an increasingly diverse, pluralist workforce (Hofstede, 2011). Organizations are made of discrete individuals, and individuals have a multi-dimensional identity construct (e.g., gender, faith tradition, race/ethnicity, sexual orientation, etc.) An employee does not leave who they are at the door when coming to the workplace. Therefore, it is unlikely that an organization designing top-down approaches based on a statistical average employee optimized for the best "culture fit" within an organization's existing culture is going to yield meaningful, sustainable improvement when cultural transformation is desired (Golden, McLeroy, Green, Earp, \& Lieberman, 2015). In fact, culture change efforts that employ a one-size-fits-all approach, may become less adept at critical future of work skills such as cognitive flexibility.

As Hofstede has stated, "culture does not exist in a tangible sense, it is a product of our imagination and is only useful in so far as far as it helps us understand and predict phenomena in the real world (Hofstede, 2011)." To this end, adapting a public health social ecological model with a cultural model may offer a transdisciplinary framework for influencing the breadth and scope of cultural transformation in organizations (Golden et al., 2015). Culture is dialogue between aspirations and traditions (Appadurai, 2004). A 2015 expert working panel of the World Health Organization acknowledges this idea of culture as "something forward-looking, even visionary ("World Health Organization," 2015)." Furthermore, the WHO identified research gaps that include the interconnection of culture, health and wellbeing; including: the extent to which survey measurements are influenced by cultural bias; how health and wellbeing can be improved by taking a culturally-responsive perspective; and opportunities for integrating narrative forms of evidence into evidence-based strategies for increasing shareholder value, diversifying entrepreneurial eco-systems and creating positive social impact ("World Health Organization," 2015).

Our proposed Cultural Wellbeing Index is designed to better understand how multi-dimensional cultural identities (e.g., gender, class, occupation, race/ethnicity, etc.) influence adoption of organizational efforts intended to improve wellbeing. The purpose of this study was to develop an instrument that could potentially measure both societal cultures and be used to inform organizational cultural practices (Hofstede, 2001).

\section{Establishing a Cultural Wellbeing Index}

Synthesizing decades of prior research, our goal was to develop a holistic, well-validated, multidimensional measure of cultural wellbeing that organizations could use to predict and nurture wellbeing of individual employees while bolstering organizational culture of inclusion and innovation. In the formulation of this study, an initial systematic literature review was conducted to identify measures that have been used to measure organizational inclusion (See Table 1). To inform this approach, we used the PEN-3 cultural 
model (Airhihenbuwa, 1990; Airhihenbuwa \& Webster, 2004). The PEN-3 Cultural Model, developed by Airhihenbuwa in 1989 to plan and develop culturally-responsive health education programs (Airhihenbuwa, 1990) is comprised of three main domains: cultural empowerment, cultural identity, and cultural relationships and expectations.

\section{Cultural Empowerment}

Cultural empowerment, an assertion of the possibilities of culture, stems from the belief that culture serves the continuum of good, indifferent, and bad (Airhihenbuwa, 1990). In developing a working model of cultural wellbeing, we translated cultural empowerment domain as sense of belonging in an individual. Research suggests that there is a direct relationship between sense of belonging and depression and hopelessness, and an indirect relationship between sense of belonging and suicidal ideation (Fisher, Overholser, Ridley, Braden, \& Rosoff, 2015). A sense of belonging has also been found to be related to physical health (Hale, Hannum, \& Espelage, 2005). A prominent instrument found for belonging was the Sense of Belonging Instrument (SOBI), a 27-item instrument that measures both the antecedents as well as the actual psychological state of possessing a sense of belonging, through two scales: the SOBI-A and SOBI-P. The SOBI is defined as "the experience of personal involvement in a system or environment so that persons feel themselves to be an integral part of that system of environment" (Hagerty \& Patusky, 1995).

\section{Cultural Identity}

Cultural identity, a cultural marker, discusses how identity influences decision-making (Airhihenbuwa, 1990). We translated cultural identity domain as hope in an individual. Hope is recognized as an important factor in health, illness, and wellbeing (Redlich-Amirav, Ansell, Harrison, Norrena, \& Armijo-Olivo, 2018). Higher hope is consistently related to better outcomes in academics, athletics, physical health, psychological adjustment, and psychotherapy (Snyder, 2002). The best metric we found for cultural identity was the State Hope Scale by Snyder et al., 1996. The State Hope Scale, a 6-item instrument that surfaces goal-directed thinking and pathway planning at a given point in time, has been found to have high internal reliability and strong construct validation (Snyder et al., 1996).

\section{Cultural Expectations and Relationships}

Cultural expectations and relationships focus on individual behavior characteristics from a sociocultural lens, such as their roles and expectations in family and societal relationships (Airhihenbuwa, 1990). We translated cultural expectations and relationships domain as trust in an individual. Research suggests that practices to increase trust, or higher levels of trust from employees, is associated with improved employee wellbeing (Alfes, Shantz, Truss, \& Soane, 2013), increased employee engagement (Alfes et al., 2013), more effective and productive employee/employer relationship, increased organizational effectiveness and productivity, improved interpersonal relationships and openness, improved communication, and higher predictability, dependability, and confidence (Mishra \& Morrissey, 1990). Trust breeds more trust, commitment, and credibility, and facilitates relationships between and within organizations, thus reducing transaction costs (Chiles \& McMackin, 1996; Robinson \& Rousseau, 1994). Employer trust is traditionally measured with a 7-item Likert scale developed by Robinson and Rousseau (1994) and is based in the theoretical framework established by Mishra in 1990 (Mishra \& Morrissey, 1990; Robinson \& Rousseau, 1994).

After the first review, we further theorized that hope, trust and belonging could serve as viable proxy metrics for inclusion, compositely predictive of employee wellbeing and characterized by measures of employee health, engagement and retention. Likewise, a second systematic literature review was conducted to understand and verify that there was not already an effective instrument for measuring diversity and inclusion in a way that could drive organizational outcomes. Our review verified that such an instrument was needed (O'Keefe, Salunkhe, Lister, Johnson, \& Edmonds, 2020). Figure 1 contains a diagram that illustrates the logic model used by the research team in linking the PEN-3 model to cultural wellbeing outcomes. 


\section{FIGURE 1}

\section{CWI LOGIC MODEL}

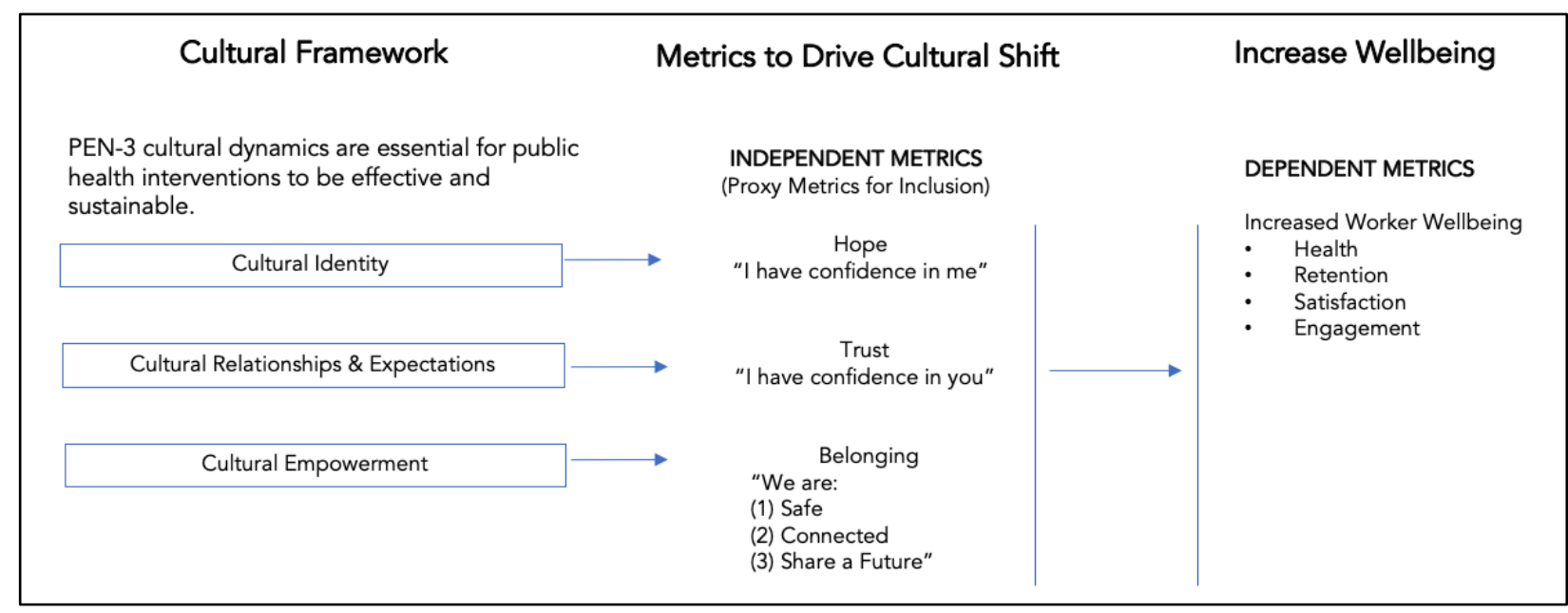

\section{Study Purpose}

In this study, the authors strive to develop and provide the first validation study for such a holistic cultural wellbeing metric that serves as the foundation for a replicable and scalable index that can be used across multiple cultural environments. This purpose of this study was to test the use and internal validity of an evidence-based index to measure the cultural health of a major U.S. corporation. Using a new composite metric, the Cultural Wellbeing Index (CWI), this study sought to do the following: 1) measure the internal validity of the CWI, and 2) determine the capacity of the CWI to predict core metrics, including employee health, retention, engagement, and job satisfaction.

\section{MATERIALS AND METHODS}

\section{Study Design and Background}

A one-time cross-sectional survey was conducted in the fall of 2019 in partnership with Home Instead, Inc., franchisor of the Home Instead Senior Care Network. The survey is a self-selected convenience sampling from the national employee database and is made up of 487 Home Instead Senior Care Network employees from the ages of 19-84. This study was approved by the Institutional Review Board (IRB) at the university where the research was sponsored (IRB number: 19.0502).

\section{Procedures and Measures}

The Cultural Wellbeing Index (CWI) survey was distributed to 7,000 Home Instead Senior Care Network employees during the months of September and October 2019. Surveys were administered electronically via the Qualtrics platform. An electronic written consent was also administered electronically prior to participants taking the survey. Only respondents who consented to have their data used in the study were able to complete the full electronic version of the survey. Two follow-up email reminders were sent via Qualtrics to complete the study. After three weeks the final responses were collected, and the survey was closed to all employees.

Basic demographic data was gathered regarding age, gender, sexuality, ethnicity, educational attainment, and religion (See Tables 2 and 3). Additionally, variables related to job role at Home Instead Senior Care Network were gathered, including job role, tenure, income, and part-time/full-time status (See Table 4). Four key study variables were measured including the health of employees, measured using health-related metrics taken from the CDC Healthy Days Module ("Centers for Disease Control and Prevention," 2000), employee engagement, employee retention, and job satisfaction (Schaufeli, Salanova, 
González-Romá, \& Bakker, 2002). Finally, the Cultural Wellbeing Index (CWI) core metric was measured using three sub-scales: 1) the Snyder Hope Scale, 2) an employer trust index, and 3) the Sense of Belonging Index (SOBI).

\section{Study Variables}

The HQROL (CDC- HQROL-4) is a 4-item self-report survey instrument that the CDC refers to as "Healthy Days"- the number of positive physical and mental health days a person reports experiencing in the previous 30 days ("Centers for Disease Control and Prevention," 2018a). The measure also accounts for the number of negative physical and mental health days a person reports 30 days prior to the survey. The HQROL is an acknowledged standard for population health surveillance by national and international groups. The main advantages of the Healthy Days measures and population data is that they relate directly to Healthy People 2020 goals; reflect known demographic and socioeconomic disparities and health patterns; reflect the burden of physical and mental illness and disability; are validated against other established measures; predict short-term mortality, hospitalizations, and physician visits; provide new insights into health behaviors; indicate important new policy-relevant disparities and trends; provide comparable population data from 1993 onward; and, are simple to measure, calculate, interpret, and add to other assessments ("Centers for Disease Control and Prevention," 2018b).

Employee engagement was measured using a seven-question index measuring participant agreement with each statement. Job satisfaction and employee retention were each measured using two-question indices similarly measuring participant agreement with set statements (See Appendix 1).

All three previously described job-related indices used a 4-point forced Likert scale with the following responses of 'Strongly disagree, 'Disagree,' 'Agree, 'and 'Strongly agree. 'A forced or binary Likert scale was used for the purpose of eliciting either a positive or negative response or firm opinion from participants. These responses were scored from 1-4, one being the lowest negative response, and 4 being the highest positive response depending on the phrasing of the question. The total score was tallied for each participant to get a final total index score for each of the three core measures. These scores were then used in the final data analysis to determine the correlation with the CWI metric.

\section{Cultural Wellbeing Index Design}

Over the course of January through April 2019, the researchers conducted several systematic reviews of the academic literature for scientifically validated measures of culture. In total, 1,265 titles and abstracts were reviewed for inclusion, with 66 full articles on the topics of belonging, hope, and trust reviewed (See Table 1). The CWI is an amalgamation of three indices that resulted from this systematic review with proven validity in the peer-reviewed literature.

TABLE 1

LITERATURE REVIEW FINDINGS ON HOPE, TRUST, AND BELONGING

\begin{tabular}{|l|c|c|l|}
\hline Table & $\begin{array}{c}\text { Number } \\
\text { of titles } \\
\text { screened }\end{array}$ & $\begin{array}{c}\text { Final } \\
\text { articles } \\
\text { reviewed }\end{array}$ & \multicolumn{1}{c|}{ Findings } \\
\hline Hope & 220 & 19 & $\begin{array}{l}\text { The majority of the included studies, 12, examine the relationship } \\
\text { between hope and wellbeing with the Snyder Hope Scale. Eight of } \\
\text { the included studies or book chapters report a positive correlation } \\
\text { between hope and physical health. Higher hope consistently is } \\
\text { related to better outcomes in academics, athletics, physical health, } \\
\text { psychological adjustment, and psychotherapy. High hope } \\
\text { individuals are also more likely to engage in positive health } \\
\text { behaviors, such as exercise, and avoid unhealthy behaviors, such as } \\
\text { smoking. Hope is positively correlated with less loneliness, greater } \\
\text { confidence, fewer negative thoughts, and more positive }\end{array}$ \\
\hline
\end{tabular}




\begin{tabular}{|l|l|l|}
\hline Trust & 760 & $\begin{array}{l}\text { Medical mistrust can range from a lack of belief in the overall } \\
\text { competency of hospitals and healthcare providers, to an active } \\
\text { belief that a patient's ethnic or societal group is specifically targeted } \\
\text { by healthcare systems and providers. There were noteworthy } \\
\text { disparities in the utilization and knowledge of important } \\
\text { preventative services, reduced satisfaction with presented treatment } \\
\text { options, and discomfort discussing options with providers in racial } \\
\text { and ethnic minorities. Medical mistrust index (MMI) was able to } \\
\text { predict underutilization of health services in patients, including } \\
\text { failure to take medical advice, failure to keep follow-up } \\
\text { appointments, postponing receiving needed care, and failure to fill } \\
\text { a prescription, though it was not predictive of failure to get needed } \\
\text { medical care. Populations with higher medical mistrust may also } \\
\text { report additional complications or comorbidities. }\end{array}$ \\
\hline Belonging & $\begin{array}{l}\text { An individual's sense of belonging can be defined as "the } \\
\text { experience of personal involvement in a system or environment so } \\
\text { that persons feel themselves to be an integral part of that system of } \\
\text { environment." A sense of belonging is critical according to the } \\
\text { PEN-3 cultural model. In each of its three domains, the PEN-3 } \\
\text { emphasizes belonging. 2 studies examining sense of belonging in } \\
\text { schools suggest improving feelings of belonging is an effective way } \\
\text { to improve the mental health of students, especially diverse } \\
\text { students. A sense of belonging was consistently found to have a } \\
\text { moderating effect on severity of depression across multiple studies. } \\
\text { 4 separate studies found that sense of belonging predicts how } \\
\text { meaningful life is perceived to be. }\end{array}$ \\
\hline
\end{tabular}

The first index is based off an employee trust index correlated with employee wellbeing, engagement, and workplace stress (Mishra \& Morrissey, 1990). Reviewed literature for this study focused on measuring trust in two major contexts: 1) medical mistrust, or level of trust within the healthcare system, and 2) employee trust in their employers and place of work. The Medical Mistrust Index (MMI) developed by LaViest et al., ranges from a five-item questionnaire to a 17-item questionnaire using a Likert scale measuring agreement with written statements (LaVeist, Nickerson, \& Bowie, 2000). Employer Trust is traditionally measured with a seven-item Likert scale developed by Robinson and Rousseau (Robinson \& Rousseau, 1994). For the purposes of this study, the researchers selected Employer Trust as it was more relevant to the study aims but recognize that medical mistrust may be a more useful tool for other cultural contexts outside of the workplace.

The second index is the Hope Scale, which is recognized as a useful predictive tool for health, illness, and wellbeing (Snyder, Irving, \& Anderson, 1991). Hope is defined as the perceived capability to derive pathways to desired goals and motivate oneself via agency thinking to use those pathways (Snyder et al., 1991). As such, hope is recognized as an important factor in health, illness, and wellbeing. Higher hope is consistently related to better outcomes in academics, athletics, physical health, psychological adjustment, and psychotherapy (Snyder et al., 1991).

The third is the Sense of Belonging Index (SOBI), which research has shown predicts physical health and health behaviors (Hagerty \& Patusky, 1995). The Sense of Belonging Instrument (SOBI) is a 27-item instrument that measures both the antecedents as well as the actual psychological state of possessing a sense of belonging, through two scales: the SOBI-A and SOBI-P, respectively. This measure differs from other similar measures of interpersonal relationships in that it encompasses and predicts other concepts, such as loneliness, social connection, depression, and conflict.

The CWI uses questions from all three of these previously described indices detailed in Table 5. Participants were asked to rate their agreement with these statements using a 4-point Likert scale like the 
one used to measure the employee metrics. These scores were appropriately scored from 1 to 4 and then scores from all three indices were totaled to create the final CWI score used in the analysis.

\section{Data Analysis}

We conducted an analysis of the survey data using SAS version 9.4. We compared rates of potential factors associated with the CWI between ethnicities, income levels, and overall employee engagement metrics using Chi-square, Pearson correlation, and T-test statistics. Individual internal metric validity was determined using a Cronbach's Alpha (See Table 5). Composite metric data was compared using Pearson Regression and simple logistic regression to determine overall inter-metric correlation. Adjusted multilogistic regression analysis was used to measure the predictive/correlative power of the CWI in relation to the four-study metrics: employee engagement, employee retention, employee satisfaction, and employee health.

\section{RESULTS}

Of the 7,000 employees that were sent a link to participate in the study, 487 completed the survey. Of the sample population, 93 percent were female, 5.76 percent were male, and less than 1 percent identified as transgender (See Table 2). The majority (66\%) reported their primary ethnicity as white, while 20 percent identified as Black, 2.5 percent as Asian, and less than 1 percent as American Indian/Alaskan Native. Around 89 percent identified as heterosexual or straight, while less than 4 percent identified as either gay, lesbian, bisexual or queer. The average age was 50 years old, with a minimum of 19 and maximum of 84 years. Over 94 percent of respondents listed their job role as Caregiver, and around 75 percent listed their income as less than $\$ 50,000$ a year (see Table 4). Around 60 percent of employees had a tenure of over 1 year, and most employees worked part-time (53\%).

TABLE 2

\section{DESCRIPTIVE STATISTICS}

\begin{tabular}{|l|c|c|c|}
\hline & Frequency & Percent & \\
\hline Gender $(\mathrm{n}=482)$ & & & \\
\hline Female & 452 & 53 & \\
\hline Male & 28 & $<1$ & \\
\hline Transgender & 2 & & \\
\hline Ethnicity (n=488) & 12 & 2.46 & \\
\hline Asian & 98 & 4.3 & \\
\hline Black or African American & 21 & 0.41 & \\
\hline Hispanic or Latino & 2 & 66.19 & \\
\hline Native American & 323 & 6.55 & \\
\hline White & 32 & & \\
\hline Other or Prefer not to answer & & 89.37 & \\
\hline Sexuality (n=488) & 437 & 0.61 & \\
\hline Heterosexual or Straight & 3 & 1.02 & \\
\hline Gay & 5 & 2.04 & \\
\hline Lesbian & 10 & 0.2 & \\
\hline Bisexual & 1 & 6.73 & \\
\hline Queer & 33 & & \\
\hline Not listed or Prefer not to answer & & 1.84 & \\
\hline Education (n=489) & 9 & 30.47 & \\
\hline Less than a high school diploma & 104 & & \\
\hline High school or equivalent & & & \\
\hline
\end{tabular}




\begin{tabular}{|l|c|c|c|}
\hline Some college but no degree & 149 & 66.19 & \\
\hline Associate degree & 72 & 14.72 & \\
\hline Bachelor's degree & 81 & 16.56 & \\
\hline Master's degree & 42 & 8.59 & \\
\hline Professional degree & 4 & 0.82 & \\
\hline Doctorate & 1 & 0.2 & \\
\hline Health & & & \\
\hline Excellent & 96 & 19.67 & \\
\hline Very Good & 220 & 45.08 & \\
\hline Good & 139 & 28.48 & \\
\hline Fair & 32 & 6.56 & \\
\hline Poor & 1 & 0.2 & Max \\
\hline Age & Average & Min & 84 \\
\hline$(n=382)$ & $50 \cdot 15$ & 19 & \\
\hline
\end{tabular}

TABLE 3

DESCRIPTIVE STATISTICS FOR HEALTHY DAYS

\begin{tabular}{|l|c|c|c|}
\hline \multicolumn{1}{|c|}{ Healthy Days (Last 30) } & Average & Standard deviation & Range \\
\hline Mental Health $(\mathrm{n}=49)$ & 2.58 & 5.92 & $0-30$ \\
\hline Physical Health $(\mathrm{n}=433)$ & 1.49 & 4.32 & $0-30$ \\
\hline Can't Perform Daily Tasks & 0.82 & 3.08 & $0-30$ \\
\hline Anxiety Days $(\mathrm{n}=415)$ & 4.22 & 8.06 & $0-30$ \\
\hline Pain Days $(\mathrm{n}=455)$ & 1.67 & 6.34 & $0-30$ \\
\hline Sad Days $(\mathrm{n}=425)$ & 2.07 & 5.15 & $0-30$ \\
\hline Enough Sleep $(\mathrm{n}=412)$ & 6.11 & 8.56 & $0-30$ \\
\hline Full of Energy $(\mathrm{n}=362)$ & 18.41 & 11.59 & $0-30$ \\
\hline
\end{tabular}

TABLE 4

\section{JOB CHARACTERISTICS}

\begin{tabular}{|l|c|c|}
\hline & Frequency & Percent \\
\hline Job Role $(\mathrm{n}=489)$ & & 94.07 \\
\hline Caregiver & 460 & 1.84 \\
\hline Management & 9 & 4.09 \\
\hline Office Support/Other & 20 & \\
\hline Income $(\mathrm{n}=481)$ & 41 & 8.52 \\
\hline Less than $\$ 10,000$ & 51 & 10.60 \\
\hline$\$ 10,000-\$ 14,999$ & 104 & 21.62 \\
\hline$\$ 15,000-\$ 24,9999$ & 92 & 19.13 \\
\hline$\$ 25,000-\$ 34,999$ & 68 & 14.14 \\
\hline$\$ 35,000-\$ 49,999$ & 73 & 15.18 \\
\hline$\$ 50,000-\$ 74,999$ & 22 & 4.57 \\
\hline$\$ 75,000-\$ 99,999$ & 30 & 6.24 \\
\hline$\$ 100,000$ or more & & \\
\hline Tenure $(\mathrm{n}=488)$ & 22 & 4.51 \\
\hline Less than 1 month & 55 & 10.25 \\
\hline 1 to 3 months & 50 & 10.25 \\
\hline 3 to 6 months & & \\
\hline
\end{tabular}




\begin{tabular}{|c|c|c|}
\hline 6 to 12 months & 70 & 14.34 \\
\hline More than 1 year & 291 & 59.63 \\
\hline Full or Part Time $(\mathrm{n}=488)$ & & \\
\hline Full time (30 hours or more) & 231 & 47.34 \\
\hline Part time (29 hours or less) & 257 & 52.66 \\
\hline
\end{tabular}

TABLE 5

CULTURAL WELLBEING INDEX SUB-SCALES (PEARSON CORRELATION P VALUE)

\begin{tabular}{|l|c|c|c|}
\hline & Health & Engagement & Retention \\
\hline Snyder Hope Scale & & & \\
\hline I can think of many ways to get out of a jam. & 0.2084 & 0.0024 & 0.2139 \\
\hline At the present time, I am energetically pursuing my goals. & 0.0101 & $<.0001$ & $<.0001$ \\
\hline $\begin{array}{l}\text { There are lots of ways around any problem that I am facing } \\
\text { now. }\end{array}$ & 0.0020 & $<.0001$ & 0.8521 \\
\hline Right now I see myself as being pretty successful. & $<.0001$ & $<.0001$ & $<.0001$ \\
\hline I can think of many ways to reach my current goals. & $<.0001$ & $<.0001$ & $<.0001$ \\
\hline At this time, I am meeting the goals I have set for myself. & $<.0001$ & $<.0001$ & $<.0001$ \\
\hline Employer Trust Scale & & & \\
\hline I am not sure I fully trust my employer. & 0.2615 & $<.0001$ & $<.0001$ \\
\hline My Employer is open and upfront with me. & 0.1687 & $<.0001$ & $<.0001$ \\
\hline I believe my employer has high integrity. & 0.0358 & $<.0001$ & $<.0001$ \\
\hline $\begin{array}{l}\text { In general, I believe my employer's motives and intentions } \\
\text { are good. }\end{array}$ & 0.1285 & $<.0001$ & $<.0001$ \\
\hline My employer is not always honest and truthful. & 0.5825 & $<.0001$ & $<.0001$ \\
\hline I don't think my employer treats me fairly. & 0.2031 & 0.0016 & $<.0001$ \\
\hline $\begin{array}{l}\text { I can expect my employer to treat me in a consistent and } \\
\text { predictable fashion. }\end{array}$ & 0.5572 & $<.0001$ & $<.0001$ \\
\hline Sense of Belonging Index & & & \\
\hline Sometimes I wonder if I really fit. & & & \\
\hline I think people accept me. & 0.0002 & $<.0001$ & $<.0001$ \\
\hline I feel that what I have to offer others is valued. & $<.0001$ & $<.0001$ & $<.0001$ \\
\hline I could disappear for days and no one would notice. & 0.0158 & $<.0001$ & $<.0001$ \\
\hline I feel like I fit in with the mainstream of society. & 0.0079 & 0.0002 & $<.0001$ \\
\hline Sometimes I feel like I observe life rather than participate. & $<.0004$ & 0.0012 & $<.0001$ \\
\hline I feel that few people would come to my funeral. & 0.0014 & 0.0126 & $<.0001$ \\
\hline $\begin{array}{l}\text { I feel like my background and experiences are the same as } \\
\text { others. }\end{array}$ & 0.1132 & 0.0703 & 0.9076 \\
\hline Sometimes I feel left out. & $<.0001$ & 0.0800 & $<.0001$ \\
\hline
\end{tabular}

\section{Internal Validity}

As shown in Table 6, both the dependent metrics (employee health, retention, engagement, and satisfaction) and the independent variables (trust, hope, and belonging) showed good to very high levels of interval validity. When grouping together the individual metrics for trust, hope, and belonging in the Cultural Wellbeing Index (CWI), the Cronbach's Alpha was 0.86. Additionally, Figure 2 shows that the individual metrics comprising the CWI had high levels of correlation using both a Pearson correlation and logistic regression. 
TABLE 6

STUDY MEASURES SUMMARY DATA

\begin{tabular}{|l|l|l|l|l|l|}
\hline & Average & Std. dev. & Range & \% Agree & $\begin{array}{l}\text { Cronbach's } \\
\text { Alpha }\end{array}$ \\
\hline Dependent Metrics & & & & & \\
\hline Employee Engagement (N=485) & 22.98 & 2.72 & $7-28$ & 71.33 & 0.765038 \\
\hline Employee Satisfaction (N=487) & 6.5 & 1.31 & $2-8$ & 75 & 0.882663 \\
\hline Employee Retention (N-485) & 6.29 & 1.54 & $2-8$ & 71.5 & 0.87915 \\
\hline CWI Metrics (Independent) & & & & & \\
\hline Employee Trust (N=486) & 22.55 & 4.08 & $7-28$ & 74.05 & 0.900136 \\
\hline Hope (N=486) & 17.98 & 2.75 & $6-24$ & 66.56 & 0.797417 \\
\hline Sense of Belonging (N=486) & 26.76 & 3.95 & $9-36$ & 65.78 & 0.779321 \\
\hline CWI (N=483) & 67.33 & 7.93 & $22-88$ & 68.68 & 0.863469 \\
\hline
\end{tabular}

FIGURE 2

CWI INTERNAL VALIDITY

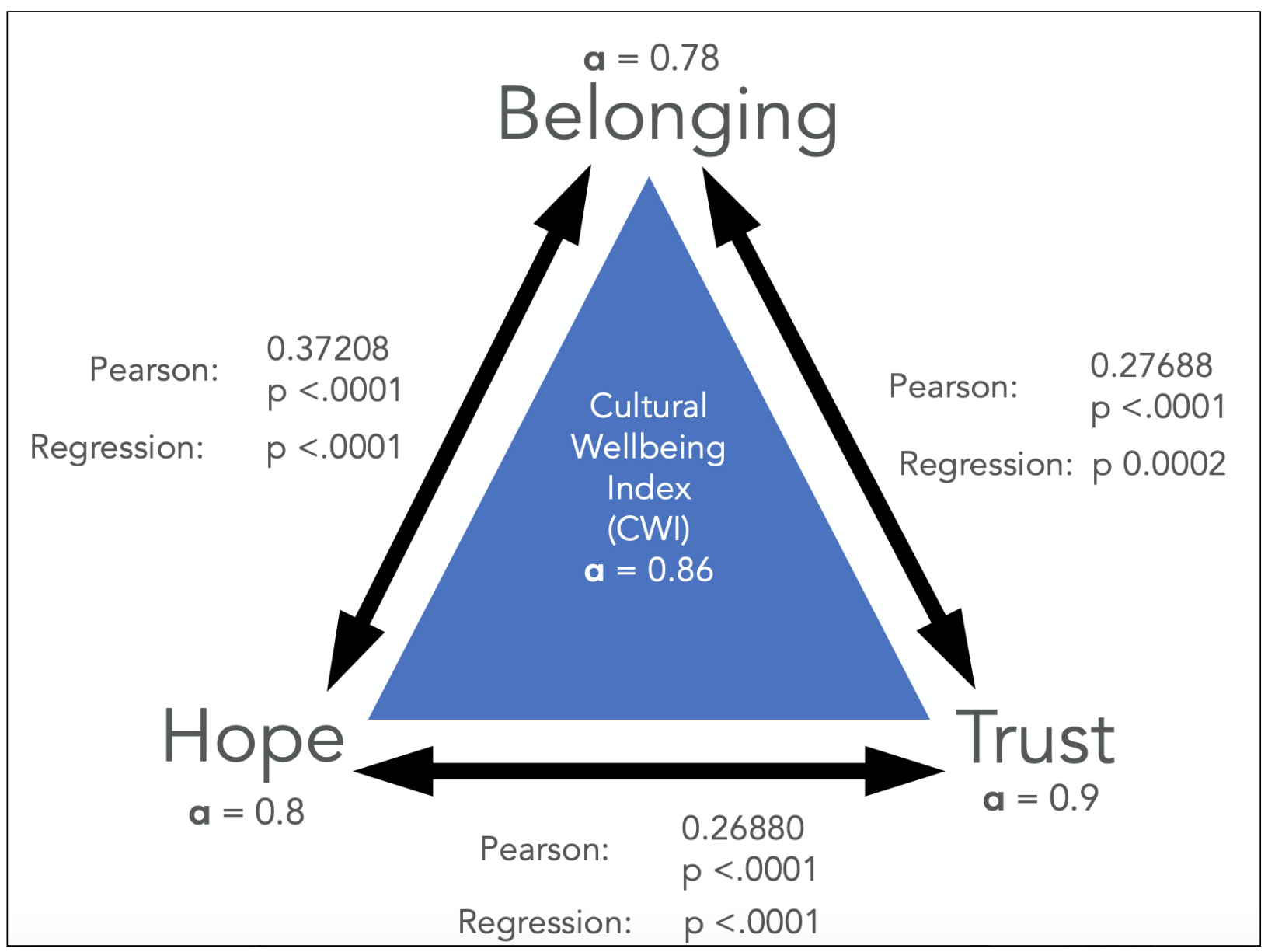

\section{Multi-Logistic Regression Analysis}

Four logistic regression models were utilized to test the correlative power of the CWI to the four study variables: employee health $(p<0.0001)$, retention $(p<0.0001)$, engagement $(p<0.0001)$, and job 
satisfaction $(\mathrm{p}<0.0001)$. Table 7 shows the results of the regression and illustrates that the CWI is highly correlated with each of the four study measures that were tested for in this study.

\section{STUDY MEASURES SUMMARY DATA}

\begin{tabular}{|l|c|c|c|c|}
\hline \multicolumn{1}{|c|}{ Variables } & $\begin{array}{c}\text { EMP } \\
\text { retention } \\
\mathbf{N = 3 8 0}\end{array}$ & $\begin{array}{c}\text { General } \\
\text { Health } \\
\mathbf{N = 3 8 0}\end{array}$ & $\begin{array}{c}\text { EMP } \\
\text { Satisfaction } \\
\mathbf{N = 3 7 9}\end{array}$ & $\begin{array}{c}\text { EMP } \\
\text { Engagement } \\
\mathbf{N = 3 7 9}\end{array}$ \\
\hline Cultural Wellbeing Index (CWI) & $<0.0001^{* *}$ & $<0.0001^{* *}$ & $<0.0001^{* *}$ & $<0.0001^{* *}$ \\
\hline General Health & 0.5842 & - & 0.9558 & - \\
\hline Ethnicity (White vs. Ethnic Minority) & $0.0202^{*}$ & 0.8753 & 0.7365 & 0.341 \\
\hline Education (College Educated vs. Not) & 0.398 & $0.0448^{*}$ & 0.151 & 0.7507 \\
\hline Full-Time vs. Part-Time Employment & 0.4288 & 0.2040 & 0.1132 & - \\
\hline Income (> \$50,000 vs. $<\$ 50,000)$ & 0.7344 & $0.0035^{*}$ & 0.5389 & 0.9087 \\
\hline Age of Participant & $0.0029^{*}$ & $0.0093^{*}$ & 0.0751 & $0.0400^{*}$ \\
\hline $\begin{array}{l}\text { Job Tenure (Over 1-year vs less than a } \\
\text { year) }\end{array}$ & 0.4419 & 0.8821 & 0.3254 & 0.6731 \\
\hline
\end{tabular}

\section{DISCUSSION}

These findings illustrate not only that the CWI is an internally valid index, but that it has strong correlative and predictive power with key employee metrics such as health, retention, engagement, and job satisfaction. Different metrics for measuring organizational culture and wellbeing exist in disparate parts across several disciplines. However, to the best of the authors' knowledge, a replicable, scalable framework that brings together the existing myriad of scientifically validated instruments to holistically measure cultural wellbeing is not yet available. Especially one that connects to business outcomes and supports replication of reliable outcomes across a diverse range of public and private sector context and organizational typologies. We believe that our resulting implications will be beneficial to businesses, researchers, and program administrators, especially in the aftermath of the current pandemic, as companies can better serve the health and wellbeing of their employees while simultaneously bolstering up cultures of inclusivity, diversity, and innovation.

This study provides the first step in creating a framework to illustrate the financial or business case for investing in the development of inclusive and diverse cultures in the workplace as an antecedent condition for wellbeing. For instance, research shows that hope, trust and belonging play a critical role in the overall health and wellbeing of populations across several domains of the ecological model: including individual, family and cultural, workplace and organizational, and societal domains. Furthermore, it was our hypothesis that hope, trust and belonging, as proxy measures for inclusion, were most likely to support eudaimonist wellbeing mindset. Eudaimonic wellbeing, which relates to meaning, self-realization and the full functioning of the person (Ryan \& Deci, 2001), are shown to enhance drivers of innovative capacity such as curiosity (Kashdan, Disabato, Goodman, \& McKnight, 2020).

Importantly, for the workforce measured in this study demographic data of the participants align well with national demographic data within this industry. Home Instead, Inc uses a franchise model and consequently was able to provide only basic statistics of its total employee population to the researchers. According to Home Instead, 78 percent of its current workforce is female, while 17 percent is male. The remaining 5 percent was not classified. Around 33 percent of their workforce is between the ages of 18 and 30 , while another third is between 31 and 50, and the remaining 33 percent is over 51 -with 6 percent 66 years of age or older. Research suggests that of all the home care workers in the U.S. in 2017, approximately 28\% were African Americans, and 23\% were Hispanic or Latino (Michas, 2019a). Also, women (87\%) made a major proportion of home care workers in the U.S (Michas, 2019b). It thus shows that the 
demographic statistics for the sample of Home Instead, Inc are in the ballpark of the national statistics for home care workers. Therefore, we believe that the external validity of the study was not compromised.

\section{CWI and Health}

A sense of belonging has consistently been found to have a moderating effect on severity of depression across multiple studies. A sense of belonging has been found to be related to better mental health among Black populations, American Indian/Alaskan Native populations, and Lesbian/Gay/Bisexual communities (Hill, 2009; Hunter, Case, Joseph, Mekawi, \& Bokhari, 2017; Rostosky, Cardom, Hammer, \& Riggle, 2018). Research has also shown a connection between a sense of belonging and better physical health and health behaviors (Hale et al., 2005). Our study further illustrated a profound link between a participantreported sense of belonging and their overall reported health.

Our study showed a strong positive correlation between the hope of respondents and their overall health. Research shows a positive correlation between hope and physical health, such as improving pain tolerance (Berg, Snyder, \& Hamilton, 2008), experiencing fewer or less severe symptoms of lung cancer (Berendes et al., 2010), lesser levels of fatigue and stress among chronically ill patients (Hirsch \& Sirois, 2016), and higher skills functioning among inpatient rehabilitation patients (Kortte, Stevenson, Hosey, Castillo, \& Wegener, 2012). Other studies have reported the role of hope in engaging in positive health behaviors, such as lower smoking and binge drinking behaviors (Berg, Ritschel, Swan, An, \& Ahluwalia, 2011), positive health behavior changes among cardiovascular patients (Feldman \& Sills, 2013), and higher levels of exercise and decreased engagement in risky sexual behaviors (Cheavens, Feldman, Gum, Michael, \& Snyder, 2006). Hope has been shown to have a significant impact on mental health, with several studies demonstrating the impact of hope on positive emotional wellbeing, and the alleviation of depressive symptoms (Munoz et al., 2018).

\section{CWI and Employee Variables}

Of all the variables studied, self-reported employee trust in the employer was the strongest individual predictor of employee retention (or intention to leave their current job role) and employee engagement. Articles that have studied the role of trust in the workplace have shown that practices to increase trust, or higher levels of trust from employees, were correlated with improved employee wellbeing, increased employee engagement, lower levels of intention to leave current job role (Mishra \& Morrissey, 1990), and improved stress levels among employees (Kelloway, Turner, Barling, \& Loughlin, 2012). Mishra and Morrisey (Mishra \& Morrissey, 1990) also identified six principle business-related benefits to improving trust within an organization that can have a direct economic impact: "a) improved communication; b) greater predictability, dependability, and confidence; c) a reduction in employee turnover; d) openness, willingness to listen and accept criticism non-defensively; e) repeat business; and f) a reduction of friction among employees." (Mishra \& Morrissey, 1990, p.444)

Secondary to this finding, hope was also highly correlated to overall retention and employee engagement. Previous research has explored the role of hope in job performance across several domains and concluded that high hope among sales employees, mortgage brokers, and management executives leads to better job performance, even after controlling for cognitive ability and self-efficacy (Peterson \& Byron, 2008).

\section{CWI and Implications for Leadership Development}

This study also supports the need for a more nuanced understanding on the role of organizational leadership in culture change management efforts. Much research has been done on the empirical linkage between leadership, performance and organizational culture (Ogbonna \& Harris, 2000). While an organization's leader is a key influencer on its culture, it may be shortsighted to accept the individual cultural norms and beliefs of a leader to be paramount or to focus on their leadership in isolation from the rest of the organization. This is especially so when considering that culture is a dynamic feedback loop of an organization's aggregated, shared characteristics which influence its response to both positive and negative environmental catalysts (Hofstede, Hofstede, \& Minkov, 2010). 
If culture can be viewed as individual values arranged as mental programs, and people's behavior as the performance of such programs (Hofstede, 1984), then to focus on the leader's role as the primary mechanism for organizational culture shift, confines organizational capacity for complex problem solving in uncertain environments to a rather limited individual view of what's possible. This potentially creates bias-induced blind spots based on the leader's own values and norms which may be out of sync with a fastchanging demographic landscape. For instance, even while America becomes more diverse, women hold only 7 percent and ethnically diverse executives represent only 9 percent of CEO positions in Fortune 500 companies (Larcker \& Tayan, 2020).

\section{Future Directions}

Individuals derive meaning and purpose from the cultures in which they participate. There is a clear, evidentiary link between culture and wellbeing. The biomedical model, with which Western culture diagnoses and defines health, is itself a cultural construct - developed in a Western culture, without regard to the perceptions of health and wellbeing held by other cultures (Napier et al., 2014). One's cultural identity mediates both perception of wellbeing and the ways in which environments, from healthcare settings to the workplace, might impact individual wellbeing. Therefore, organizational efforts and structures - from programs to improve employee health to those seeking to boost productivity - should account for the myriad of multi-dimensional cultural constructs employees carry. This seems especially important to the functioning of a pluralist society.

Precision in data could help companies to better understand how their workforce constructs identity and to map the competing value systems at play in order to unlock underestimated talent operating differently from non-dominant cultural frames. The main issue of concern is to be able to measure and implement changes to better influence diverse and inclusive workplaces, and thus positively impact organizational performance through improved employee wellbeing. Single indicator metrics fail to capture the myriad of inputs that shape culture, and so we propose a multi-factor index that incorporates hope, trust, and belonging as indicators of an organization's cultural wellbeing.

The goal of this research is to close the gap between public health investment, cultural wellbeing, and economic growth of corporations, as well as the individual wellbeing and personal growth of employees.

We will continue to study this metric in various contexts, including:

1. Studying the CWI across other sectors of employment, and with a broader spectrum of participants (e.g., larger minority populations, more diverse gender population);

2. Assessing other dependent variables, such as marital/domestic partnership status, workplace autonomy, work-related stress, and employee benefit offerings;

3. Studying a population that reports overall poorer health in order to understand the impact of CWI on health;

4. Studying the longitudinal predictive capacity of positive change in CWI and the ability to predict financial outcomes of corporations; and

5. Studying the capacity of the CWI to predict overall innovation output within corporations.

\section{Study Limitations}

Although this study provides a good first step in uncovering the predictive capacity of the CWI, there was not a large enough distribution of responses to accurately measure the impact of the following variables: gender, sexuality, job role (management vs. employee), religion, and workplace geographic region.

Additionally, general health, as measured by the CDC Healthy Days Module, was limited in its power due to only one respondent listing their health as 'Poor. 'Overall, based on the CDC metrics, this population seemed to consider themselves quite healthy (See Table 3). Furthermore, the sample was derived from a group of 500 employees who self-selected to participate from a total of over 7000 employees messaged for recruitment. As such, results should be interpreted within the context of a potential self-selection bias. Additionally, the survey was optional for employees and no incentive was given for participation, which may further explain the low completion rate among employees; results should be interpreted in this context. 
Further research is needed with a higher participation rate in order to fully solidify the findings of this study and CWI metric. However, population demographics are mostly aligned with national statistics in the homecare industry as well as the demographics of workers at Home Instead Senior Care Network as a whole - with the study population having similar female to male ratios, racial breakdowns, and overall educational attainment (Hunter et al., 2017; Michas, 2019b). Finally, it should be noted that correlation with employee retention was measured using self-reported intent to leave the organization, and not actual retention rates of survey participants.

\section{CONCLUSION}

We call for business leaders to renew their commitment to employees and communities by designing and delivering authenticity, and to take employee engagement and corporate social responsibility programs from a mix of surveys and volunteerism to a scientifically grounded cultural performance pillar that drives innovation and growth. This study indicates that health, wellbeing, and capacity for organizational innovation and market performance, are scientifically connected to cultural metrics of hope, trust, and belonging.

The proposed Cultural Wellbeing Index (CWI) does not represent a new "program," but rather, a new, scientific process to reconfigure existing assets in a way that successfully navigates culturally-fluid business landscapes comprised of a diverse American workforce. We aim to make the CWI a "compass" which restores our ability to link to each other across competing value systems. The cultural shifts and shocks facing American institutions are many and varied. At the heart of these challenges is a critical transformation from focusing on shareholder profits, to the health and wellbeing of employees and their diverse communities. The CWI, we believe, will serve as a steppingstone for organizations to diagnose and treat the cause, rather than the symptom, of static innovation and growth. In fact, one organization's advantage over another in a competitive market may well depend on its cultural wellbeing.

\section{ACKNOWLEDGEMENTS}

This report was guided by and developed with the assistance of Home Instead Senior Care. This manuscript is based upon work supported by the National Science Foundation under Grant No.1738359. Additionally, funding was received from the NSF-CHOT membership fee paid by Home Instead Inc. Any opinions, findings, and conclusions or recommendations expressed in this material are those of the authors and do not necessarily reflect the views of the National Science Foundation.

\section{CONFLICT OF INTEREST}

Theodore Edmonds and Cameron Lister have incorporated a for-profit entity to commercialize the IP created inside the university; however, this research was conducted by the University of Louisville prior to the for-profit's incorporation. The purpose of this entity is to serve as cultural analytics and strategy company humanizing the future of work. The entity, Underestimated People of Purpose (UPOP), is organized as an LGBT-certified business enterprise and also as a Public Benefit Corporation in the state of Kentucky. UPOP and the University of Louisville have now finalized a tech transfer agreement for the licensing of the CWI for commercial purposes. Hannah Payne serves on the Board of Directors for this company. 


\section{REFERENCES}

Airhihenbuwa, C.O. (1990). A conceptual model for culturally appropriate health education programs in developing countries. Int $Q$ Community Health Educ, 11(1), 53-62. doi:10.2190/lpkh-pmpjdbw9-fp6x

Airhihenbuwa, C.O., \& Webster, J.D. (2004). Culture and African contexts of HIV/AIDS prevention, care and support. Sahara J, 1(1), 4-13. doi:10.1080/17290376.2004.9724822

Aldana, S. (2020). Wellness ROI vs VOI: The best employee wellbeing programs use both. Wellsteps. Retrieved from https://www.wellsteps.com/blog/2020/01/02/wellness-roi-employee-wellbeingprograms/

Alfes, K., Shantz, A.D., Truss, C., \& Soane, E.C. (2013). The link between perceived human resource management practices, engagement and employee behaviour: A moderated mediation model. The International Journal of Human Resource Management, 24(2), 330-351. doi:10.1080/09585192.2012.679950

Appadurai, A. (2004). The Capacity to Aspire: Culture and the Terms of Recognition. In V. Rao \& M. Walton (Eds.), Culture and Public Action (pp. 59-84).

Berendes, D., Keefe, F.J., Somers, T.J., Kothadia, S.M., Porter, L.S., \& Cheavens, J.S. (2010). Hope in the context of lung cancer: Relationships of hope to symptoms and psychological distress. J Pain Symptom Manage, 40(2), 174-182. doi:10.1016/j.jpainsymman.2010.01.014

Berg, C.J., Ritschel, L.A., Swan, D.W., An, L.C., \& Ahluwalia, J.S. (2011). The role of hope in engaging in healthy behaviors among college students. Am J Health Behav, 35(4), 402-415. doi:10.5993/ajhb.35.4.3

Berg, C.J., Snyder, C.R., \& Hamilton, N. (2008). The Effectiveness of a Hope Intervention in Coping with Cold Pressor Pain. Journal of Health Psychology, 13(6), 804-809. doi:10.1177/1359105308093864

Berry, L.L., Mirabito, A.M., \& Baun, W.B. (2010). What's the hard return on employee wellness programs? Harv Bus Rev, 88(12), 104-112, 142.

Centers for Disease Control and Prevention. (2000). Measuring Healthy Days: Population Assessment of Health-Related Quality of Life. U.S. Department of health and human Services. National Center for Chronic Disease Prevention and Health promotion. Division of Adult and Community Health. Retrieved from https://www.cdc.gov/hrqol/pdfs/mhd.pdf

Centers for Disease Control and Prevention. (2018a). Health-Related Quality of Life (HRQOL). Methods and Measures. Retrieved from https://www.cdc.gov/hrqol/methods.htm

Centers for Disease Control and Prevention. (2018b). Health-Related Quality of Life (HRQOL). HRQOL Concepts. Retrieved from https://www.cdc.gov/hrqol/concept.htm

Champion, V.L., \& Skinner, C.S. (2008). The health belief model. In Health behavior and health education: Theory, research, and practice (4th ed., pp. 45-65). San Francisco, CA, US: JosseyBass.

Cheavens, J.S., Feldman, D.B., Gum, A., Michael, S.T., \& Snyder, C.R. (2006). Hope therapy in a community sample: A pilot investigation. Social Indicators Research, 77(1), 61-78. doi:10.1007/s11205-005-5553-0

Chiles, T.H., \& McMackin, J.F. (1996). Integrating Variable Risk Preferences, Trust, and Transaction Cost Economics. The Academy of Management Review, 21(1), 73-99. doi:10.2307/258630

Desalvo, K., Wang, Y., Harris, A., Auerbach, J., Koo, D., \& O’Carroll, P. (2017). Public Health 3.0: A Call to Action for Public Health to Meet the Challenges of the 21st Century. Preventing Chronic Disease, 14.

Feldman, D.B., \& Sills, J.R. (2013). Hope and cardiovascular health-promoting behaviour: Education alone is not enough. Psychol Health, 28(7), 727-745. doi:10.1080/08870446.2012.754025

Fisher, L.B., Overholser, J.C., Ridley, J., Braden, A., \& Rosoff, C. (2015). From the Outside Looking In: Sense of Belonging, Depression, and Suicide Risk. Psychiatry, 78(1), 29-41. doi:10.1080/00332747.2015.1015867 
Fogg, B.J. (2009). A behavior model for persuasive design. Paper presented at the Persuasive ' 09.

Fry, E. (2020). Is it time for your business to hire a chief public health officer? Fortune. Retrieved from https://fortune.com/2020/07/08/chief-public-health-officer-business-coronavirus-amc-movietheaters/

Gallup. (2017). State of the American Workplace. Retrieved from https://www.gallup.com/workplace/238085/state-american-workplace-report-2017.aspx

Gallup. (2018). Get the Most Out of Your Culture. Retrieved from https:/www.gallup.com/workplace/232682/culture-paper-2018.aspx

Golden, S.D., McLeroy, K.R., Green, L.W., Earp, J.A., \& Lieberman, L.D. (2015). Upending the social ecological model to guide health promotion efforts toward policy and environmental change. Health Educ Behav, 42(1 Suppl), 8s-14s. doi:10.1177/1090198115575098

Hagerty, B.M., \& Patusky, K. (1995). Developing a measure of sense of belonging. Nurs Res, 44(1), 913.

Hale, C.J., Hannum, J.W., \& Espelage, D.L. (2005). Social support and physical health: The importance of belonging. J Am Coll Health, 53(6), 276-284. doi:10.3200/jach.53.6.276-284

Harvard School of Public Health. (2020). Bringing a public health focus to the business world. Retrieved from https://www.hsph.harvard.edu/news/hsph-in-the-news/bringing-a-public-health-focus-tothe-business-world/

Hill, D.L. (2009). Relationship between sense of belonging as connectedness and suicide in American Indians. Arch Psychiatr Nurs, 23(1), 65-74. doi:10.1016/j.apnu.2008.03.003

Hirsch, J.K., \& Sirois, F.M. (2016). Hope and fatigue in chronic illness: The role of perceived stress. $J$ Health Psychol, 21(4), 451-456. doi:10.1177/1359105314527142

Hofstede, G. (1984). Culture's consequences: International differences in work-related values. Sage.

Hofstede, G. (2001). Culture's consequences: Comparing values, behaviors, institutions and organizations across nations (Second ed.). Sage Publications.

Hofstede, G. (2011). National Cultures, Organizational Cultures, and the Role of Management.

Hofstede, G., Hofstede, G.J., \& Minkov, M. (2010). Cultures and organizations: Software of the mind: intercultural cooperation and its importance for survival. McGraw-Hill.

Human Rights Campaign Foundation. (2019). CORPORATE EQUALITY INDEX 2019: Rating workplaces on lesbian, gay, bisexual, transgender and queer equality. Retrieved from https://assets2.hrc.org/files/assets/resources/CEI-2019-FullReport.pdf

Hunter, C.D., Case, A.D., Joseph, N., Mekawi, Y., \& Bokhari, E. (2017). The roles of shared racial fate and a sense of belonging with African Americans in Black immigrants' race-related stress and depression. Journal of Black Psychology, 43(2), 135-158. doi:10.1177/0095798415627114

Jarrahi, M.H. (2018). Artificial intelligence and the future of work: Human-AI symbiosis in organizational decision making. Business Horizons, 61(4), 577-586. doi:https://doi.org/10.1016/j.bushor.2018.03.007

Jones, D., Molitor, D., \& Reif, J. (2019). What do Workplace Wellness Programs do? Evidence from the Illinois Workplace Wellness Study. Q. J. Econ., 134(4), 1747-1791. doi:10.1093/qje/qjz023

Kagawa Singer, M. (2012). Applying the concept of culture to reduce health disparities through health behavior research. Preventive Medicine, 55(5), 356-361. doi:https://doi.org/10.1016/j.ypmed.2012.02.011

Kaiser Family Foundation, Claxton, G., Rae, M., Long, M., \& Damico, A. (2018). Employer Health Benefits - 2018 Annual Survey. Retrieved from http://files.kff.org/attachment/Report-EmployerHealth-Benefits-Annual-Survey-2018

Kashdan, T.B., Disabato, D.J., Goodman, F.R., \& McKnight, P.E. (2020). The Five-Dimensional Curiosity Scale Revised (5DCR): Briefer subscales while separating overt and covert social curiosity. Personality and Individual Differences, 157, 109836. doi:https://doi.org/10.1016/j.paid.2020.109836 
Kelloway, E.K., Turner, N., Barling, J., \& Loughlin, C. (2012). Transformational leadership and employee psychological well-being: The mediating role of employee trust in leadership. Work \& Stress, 26(1), 39-55. doi:10.1080/02678373.2012.660774

Kohll, A. (2018). The biggest roadblock to improving employee wellbeing. Forbes. Retrieved from https://www.forbes.com/sites/alankohll/2018/09/18/the-biggest-roadblock-to-improvingemployee-well-being/?sh=73db16bae0d3

Kortte, K.B., Stevenson, J.E., Hosey, M.M., Castillo, R., \& Wegener, S.T. (2012). Hope predicts positive functional role outcomes in acute rehabilitation populations. Rehabil Psychol, 57(3), 248-255. doi: $10.1037 / \mathrm{a} 0029004$

Larcker, D.F., \& Tayan, B. (2020). Diversity in the C-Suite: The Dismal State of Diversity Among Fortune 100 Senior Executives. Stanford University Closer Look Series.

LaVeist, T.A., Nickerson, K.J., \& Bowie, J.V. (2000). Attitudes about racism, medical mistrust, and satisfaction with care among African American and white cardiac patients. Med Care Res Rev, 57(Suppl 1), 146-161. doi:10.1177/1077558700057001s07

Lieberman, C. (2019). What wellness programs don't do for workers. Harvard Business Review. Retrieved from https://hbr.org/2019/08/what-wellness-programs-dont-do-for-workers

Matsuura, K. (2005). Appendix I UNESCO Universal Declaration on Cultural Diversity UNESCO Universal Declaration on Cultural Diversity. Diogenes, 52(1), 141-145.

Mattke, S., Liu, H.H., Caloyeras, J.P., Huang, C.Y., Van Busum, K.R., Khodyakov, D., . . Broderick, M. (2014). RAND Corporation. Do workplace wellness programs save employers money? Retrieved from https://www.shrm.org/ResourcesAndTools/hrtopics/benefits/Documents/RAND_RB9744.pdf

Michas, F. (2019a). Distribution of home care workers in the U.S. in 2017, by ethnicity. Statista. Retrieved from https://www.statista.com/statistics/720230/home-care-workers-united-states-byethnicity/

Michas, F. (2019b). Distribution of home care workers in the U.S. in 2017, by gender. Statista. Retrieved from https://www.statista.com/statistics/720087/home-care-workers-united-states-by-gender/

Mishra, J., \& Morrissey, M.A. (1990). Trust in employee/employer relationships: A survey of West Michigan managers. Public Personnel Management, 19(4), 443-486. doi:10.1177/009102609001900408

Munoz, R.T., Pearson, L.C., Hellman, C.M., McIntosh, H.C., Khojasteh, J., \& Fox, M.D. (2018). Adverse childhood experiences and posttraumatic stress as an antecedent of anxiety and lower hope. Traumatology, 24(3), 209-218. doi:10.1037/trm0000149

Napier, A.D., Ancarno, C., Butler, B., Calabrese, J., Chater, A., Chatterjee, H., .. W Woolf, K. (2014). Culture and health. Lancet, 384(9954), 1607-1639. doi:10.1016/s0140-6736(14)61603-2

O'Keefe, M., Salunkhe, S.S., Lister, C., Johnson, C., \& Edmonds, T. (2020). Quantitative and Qualitative Measures to Assess Organizational Inclusion: A Systematic Review. Journal of Business Diversity, 20(5), 49-70. doi:https://doi.org/10.33423/jbd.v20i5.3928

Ogbonna, E., \& Harris, L. (2000). Leadership style, organizational culture and performance: Empirical evidence from UK companies. The International Journal of Human Resource Management, 11, 766-788.

Peterson, S.J., \& Byron, K. (2008). Exploring the role of hope in job performance: Results from four studies. Journal of Organizational Behavior, 29(6), 785-803. doi:10.1002/job.492

Prochaska, J.O., \& Velicer, W.F. (1997). The transtheoretical model of health behavior change. Am J Health Promot, 12(1), 38-48. doi:10.4278/0890-1171-12.1.38

Redlich-Amirav, D., Ansell, L.J., Harrison, M., Norrena, K.L., \& Armijo-Olivo, S. (2018). Psychometric properties of Hope Scales: A systematic review. Int J Clin Pract, 72(7), e13213. doi:10.1111/ijcp.13213

Roadmap \& Assessment Report. (2019). Techstars Startup Ecosystems Development Program. Retrieved from https://media.bizj.us/view/img/11267413/12-louisville-ky-roadmap-and-assessment-finalreportdigitalpublic-use-approved.pdf 
Robinson, S.L., \& Rousseau, D.M. (1994). Violating the psychological contract: Not the exception but the norm. Journal of Organizational Behavior, 15(3), 245-259. doi:10.1002/job.4030150306

Robinson, W.S. (2009). Ecological Correlations and the Behavior of Individuals*. International Journal of Epidemiology, 38(2), 337-341. doi:10.1093/ije/dyn357

Rostosky, S.S., Cardom, R.D., Hammer, J.H., \& Riggle, E.D.B. (2018). LGB positive identity and psychological well-being. Psychology of Sexual Orientation and Gender Diversity, 5(4), 482489. doi:10.1037/sgd0000298

Ryan, R.M., \& Deci, E.L. (2001). On happiness and human potentials: A review of research on hedonic and eudaimonic well-being. Annu Rev Psychol, 52, 141-166. doi:10.1146/annurev.psych.52.1.141

Schaufeli, W.B., Salanova, M., González-Romá, V., \& Bakker, A.B. (2002). The measurement of engagement and burnout: A two sample confirmatory factor analytic approach. Journal of Happiness Studies: An Interdisciplinary Forum on Subjective Well-Being, 3(1), 71-92. doi:10.1023/A:1015630930326

Seligman, M. (2018). PERMA and the building blocks of well-being. The Journal of Positive Psychology, 13(4), 333-335. doi:10.1080/17439760.2018.1437466

Smith, C., \& Yoshino, K. (2019). Deloitte. Uncovering Talent: A new model of inclusion. Retrieved from https://www2.deloitte.com/content/dam/Deloitte/us/Documents/about-deloitte/us-about-deloitteuncovering-talent-a-new-model-of-inclusion.pdf

Snyder, C.R. (2002). Hope theory: Rainbows in the mind. Psychological Inquiry, 13(4), 249-275. doi:10.1207/S15327965PLI1304 01

Snyder, C.R., Irving, L.M., \& Anderson, J.R. (1991). Hope and health. In Handbook of social and clinical psychology: The health perspective (pp. 285-305). Elmsford, NY, US: Pergamon Press.

Snyder, C.R., Sympson, S.C., Ybasco, F.C., Borders, T.F., Babyak, M.A., \& Higgins, R.L. (1996). Development and validation of the State Hope Scale. J Pers Soc Psychol, 70(2), 321-335. doi:10.1037//0022-3514.70.2.321

Song, Z., \& Baicker, K. (2019). Effect of a Workplace Wellness Program on Employee Health and Economic Outcomes: A Randomized Clinical Trial. JAMA, 321(15), 1491-1501. doi:10.1001/jama.2019.3307

Trompenaars, A. (1993). Riding the Waves of Culture: Understanding Diversity in Global Business.

U.S. Chamber of Commerce Foundation. (2019). Business Success and Growth through LGBT-inclusive culture. Retrieved from https://www.uschamberfoundation.org/sites/default/files/BusinessSuccess-Growth-LGBT-Inclusive-Culture-FINAL-WEB.pdf

World Health Organization. (2015). Beyond Bias: Exploring the cultural contexts of health and wellbeing measurement. Retrieved from https://www.euro.who.int/_data/assets/pdf_file/0008/284903/Cultural-contexts-health.pdf 


\section{APPENDIX 1}

\section{Study Measures: Engagement, Retention, and Job Satisfaction}

\section{Employee Engagement Questions}

Q1. When I get up in the morning, I feel like going to work.

Q2. To me, my job is challenging.

Q3. My job inspires me.

Q4. I am enthusiastic about my job.

Q5. I am proud on the work that I do.

Q6. I find the work that I do full of meaning and purpose.

Q7. At my work I always persevere, even when things do not go well.

Employee Retention

Q1. I am seriously considering quitting this firm for an alternative employer.

Q2. During the next year, I will probably look for a new job outside this firm

Job Satisfaction

Q1. Working for this organization is very satisfying to me.

Q2. I am satisfied with this job. 